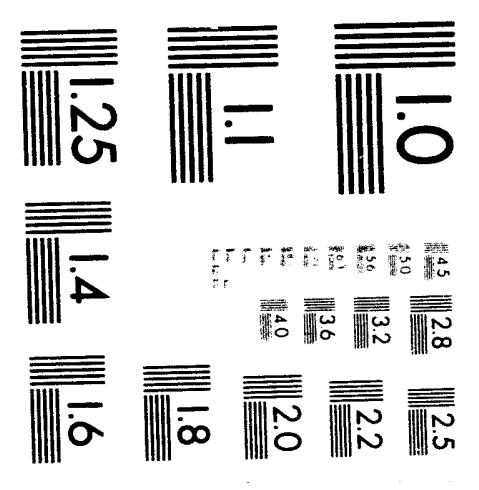



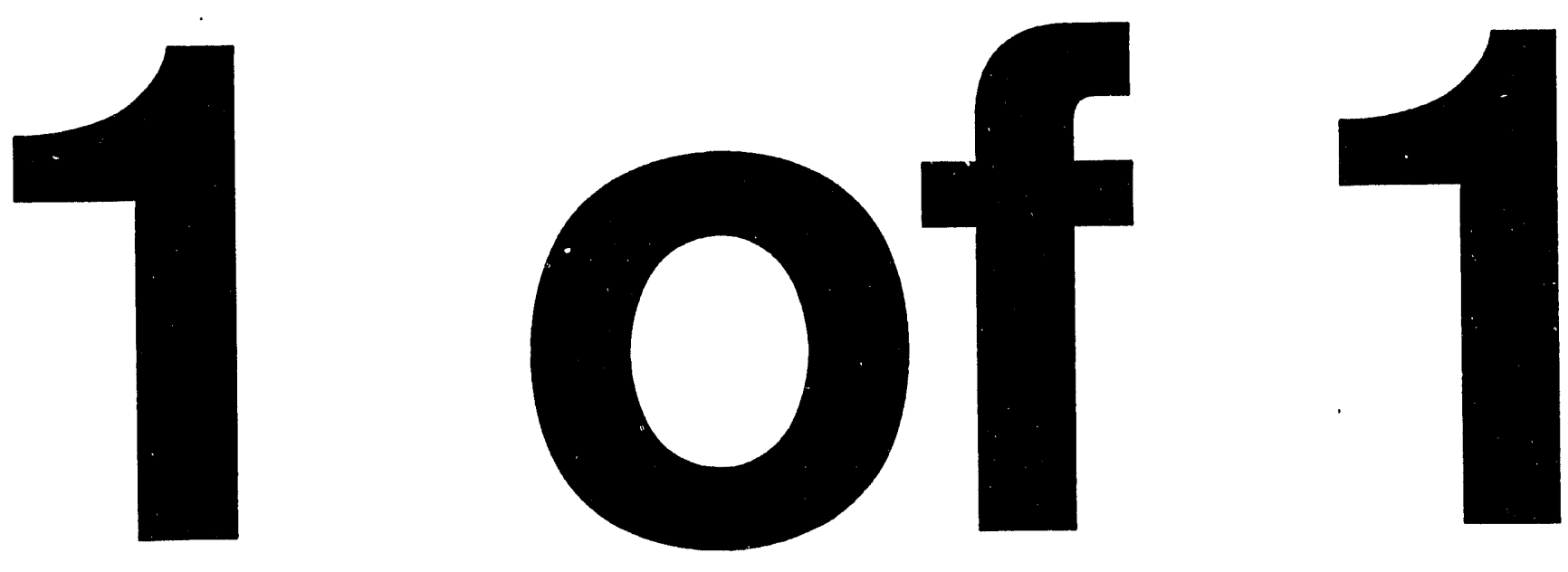
NUREG/CR-4469

PNL-5711

Vol. 15

R5

\section{Nondestructive Examination \\ (NDE) Reliability for \\ Inservice Inspection of \\ Light Water Reactors}

Semiannual Report

October 1991 - March 1992

Manuscript Completed: August 1993

Date Published: September 1993

Prepared by

S. R. Doctor, A. A. Diaz, J. R. Friley, M. S. Good,

M. S. Greenwood, P. G. Heasler, R. L. Hockey, R. J. Kurtz,

F. A. Simonen, J. C. Spanner, T. T. 'Raylor, T. V. Vo

Pacific Northwest Laboratory

Richland. WA 99352

Prepared for

Division of Engineering

Office of Nuclear Regulatory Research

U.S. Nuclear Regulatory Commission

Washington, DC 20555-0001

NRC FIN B2289 


\begin{abstract}
The Evaluation and Improvement of NDE Reliability for Inservice Inspection of Light Water Reactors (NDE Reliability) Program at the Pacific Northwest Laboratory was established by the Nuclear Regulatory Commission to determine the reliability of current inservice inspection (ISI) techniques and to develop recommendations that will ensure a suitably high inspection reliability. The objectives of this program include determining the reliability of ISI performed on the primary systems of commercial light-water reactors (LWRs); using probabilistic fracture mechanics analysis to deter-

and evaluating reliability improvements that can be achieved with improved and advanced technology. A final objective is to formulate recommended revisions to the Regulatory and ASME Code requirements, based on matcrial properties, service conditions, and NDE uncertainties. The program scope is limited to ISI of the primary systems including the piping, vessel, and other components inspected in accordance with Section $\mathrm{XI}$ of the ASME Code. This is a progress report covering the programmatic work from October 1991 through March 1992.
\end{abstract} mine the impact of NDE unreliability on system safety; 


\section{Contents}

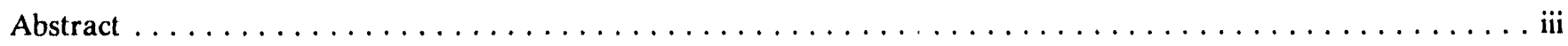

Executive Summary $\ldots \ldots \ldots \ldots \ldots \ldots \ldots \ldots \ldots \ldots \ldots \ldots \ldots \ldots \ldots \ldots \ldots \ldots \ldots \ldots \ldots \ldots \ldots \ldots$

Previous Reports in Series $\ldots \ldots \ldots \ldots \ldots \ldots \ldots \ldots \ldots \ldots \ldots \ldots \ldots \ldots \ldots \ldots \ldots \ldots \ldots \ldots \ldots$

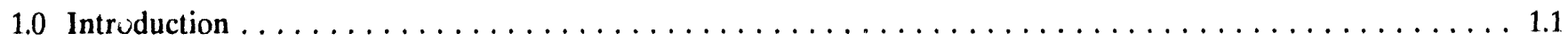

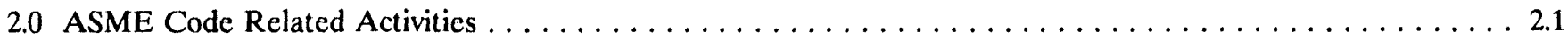

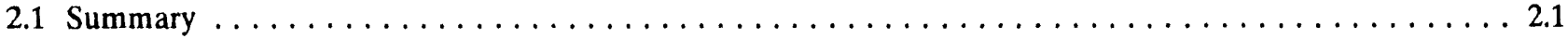

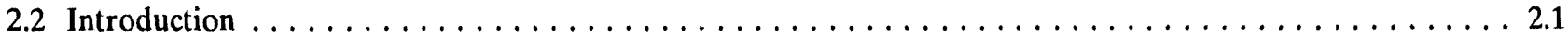

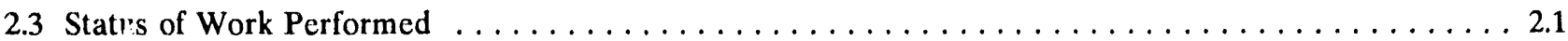

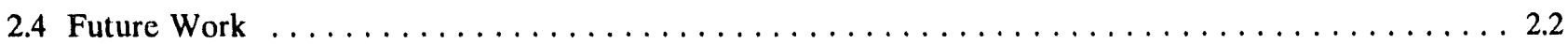

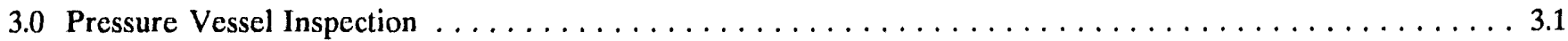

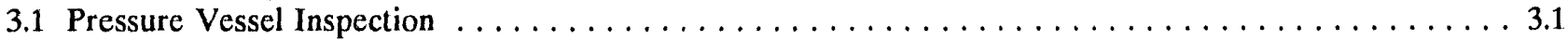

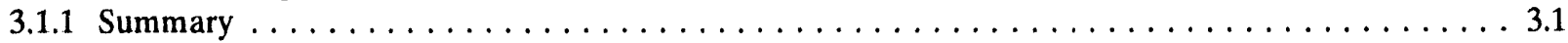

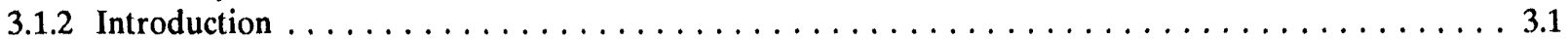

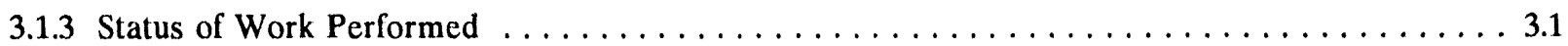

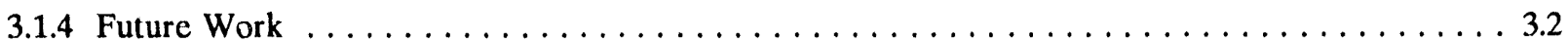

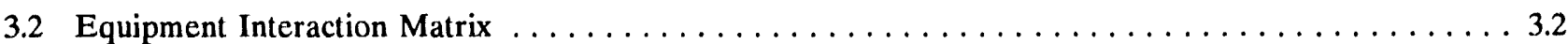

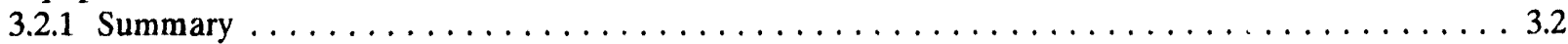

3.2 .2 Introduction $\ldots \ldots \ldots \ldots \ldots \ldots \ldots \ldots \ldots \ldots \ldots \ldots \ldots \ldots \ldots \ldots \ldots \ldots \ldots \ldots \ldots \ldots \ldots \ldots \ldots \ldots \ldots \ldots \ldots, 2$

3.2 .3 Status of Work Performed $\ldots \ldots \ldots \ldots \ldots \ldots \ldots \ldots \ldots \ldots \ldots \ldots \ldots \ldots \ldots \ldots \ldots \ldots \ldots \ldots \ldots \ldots \ldots \ldots, 2$

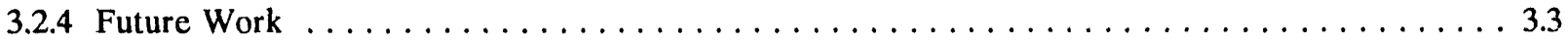

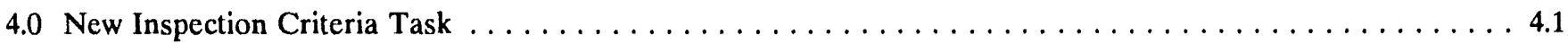

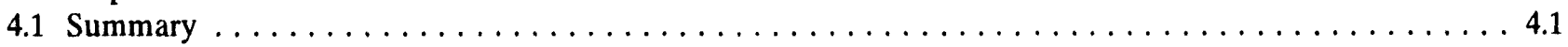

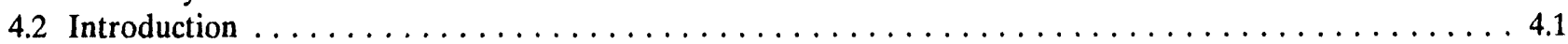

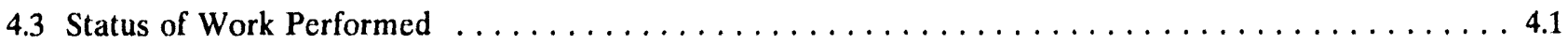

4.3.1 ASME Task Force on Risk-Based Inspection Guidelines $\ldots \ldots \ldots \ldots \ldots \ldots \ldots \ldots \ldots \ldots .1$

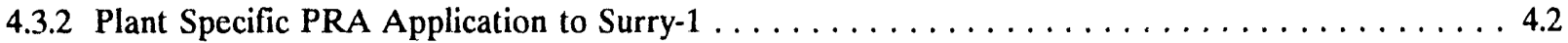

4.3.3 Expert Judgement Elicitation for Rupture Probabilities $\ldots \ldots \ldots \ldots \ldots \ldots \ldots \ldots \ldots \ldots 4.3$

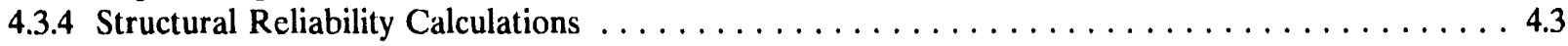

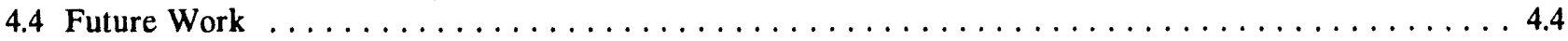

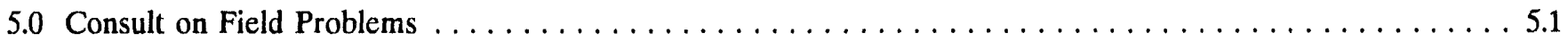

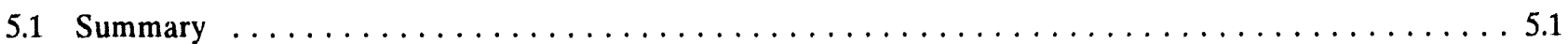

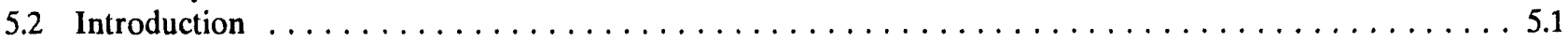

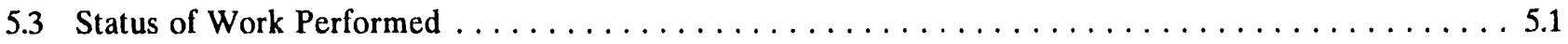

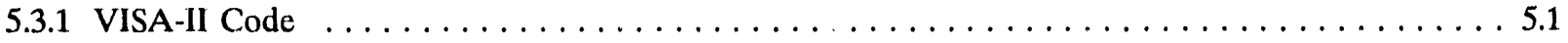

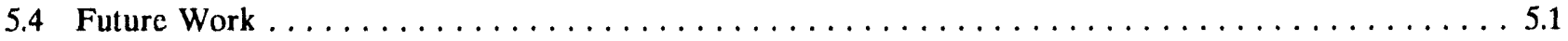


Contents

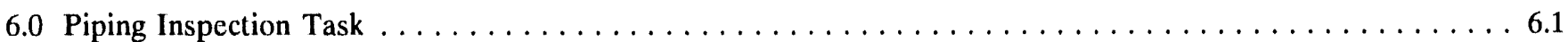

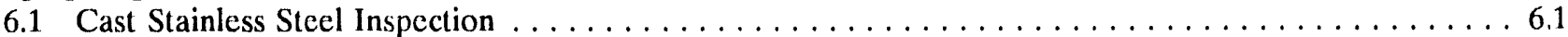

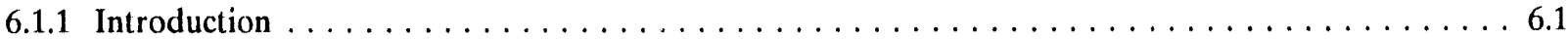

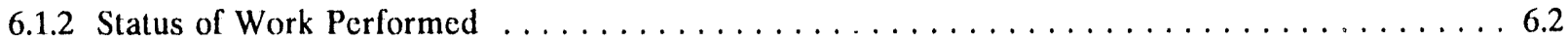

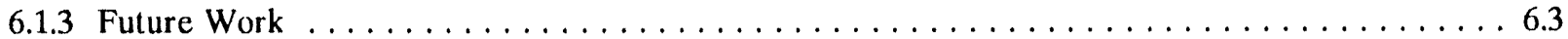

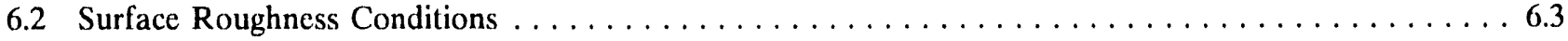

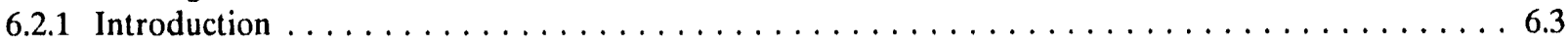

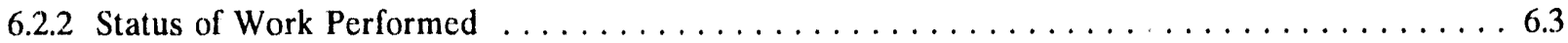

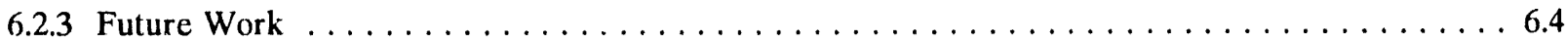

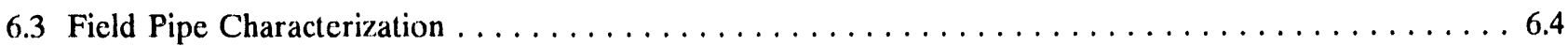

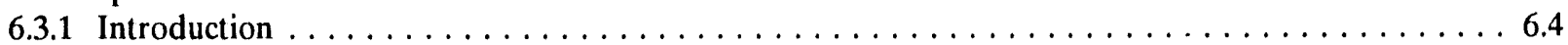

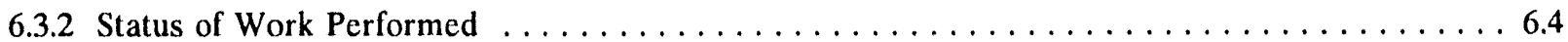

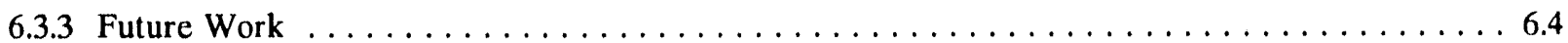

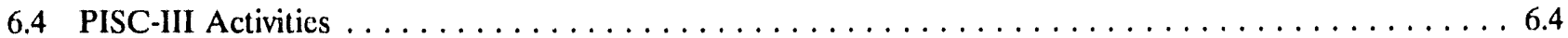

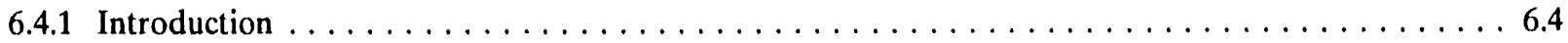

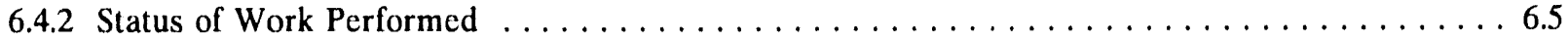

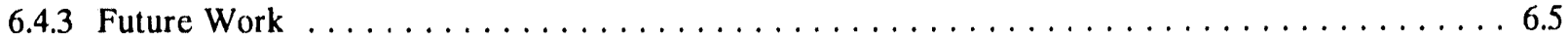

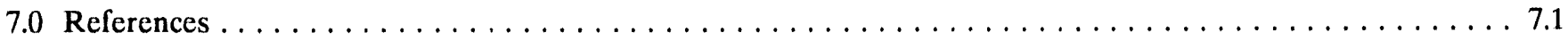

Tables

4.1. List of Expert Attendees at Rupture Probability Judgement Elicitation Workshop $\ldots \ldots \ldots \ldots \ldots .6$

4.2. Pressurized Water Reactor Pressure Vessel Inspection Strategy $\ldots \ldots \ldots \ldots \ldots \ldots \ldots \ldots \ldots \ldots \ldots .7$

4.3. Effect of Inspection on Thermal Fatigue in Auxiliary Feedwater Piping $\ldots \ldots \ldots \ldots \ldots \ldots \ldots \ldots$ 


\section{Executive Summary ${ }^{1}$}

A multi-year program entitled the Evaluation and Improvement of NDE Reliability for Inservice Inspection of Light Water Reactors (NDE Reliability) was established at the Pacific Northwest Laboratory (PNL) to determine the reliability of current inservice inspection (ISI) techniques and to develop recommendations that would ensure a suitably high inspection reliability if fully implemented.

The objectives of this Nondestructive Examination (NDE) Reliability program for the Nuclear Regulatory Commission (NRC) include:

- Determine the reliability of ultrasonic ISI performed on the primary systems of commercial light-water reactors (LWRs).

- Use probabilistic fracture mechanics analysis to determine the impact of NDE unrcliability on system safety and determine the level of inspection reliability required to ensure a suitably low failure probability.

- Evaluate the degree of reliability improvement that could be achieved using improved and advanced NDE techniques.

- Based on material properties, service conditions, and NDE uncertainties, formulate recommended revisions to Sections XI and V of the ASME Code and the Regulatory requirements needed to ensure suitably low failure probabilities.

The scope of the program is limited to the ISI of primary coolant systems, but the results and recommendations are also applicable to Class 2 piping systems.

The program consists of three basic tasks: a Piping task, a Pressure Vessel task, and a New Inspection Criteria task. The major highlights during this reporting period were:

- ASME Code Activity

Participation in ASME Section XI activities continued toward achieving Code acceptance of NRC-

$1_{\text {RSR FIN. Budget No. B2289; RSR Contact: J. Muscara }}$ funded PNL research results to improve the reliability of nondestructive evaluation/inservice inspection (NDE/ISI). The most significant success was in getting the SAFT technology into the methodology of Section V.

\section{- Pressure Vessel Activities}

Re-analysis of PISC-II Data. The objective of this task is to determine the capability of U.S. ultrasonic inservice inspection of reactor pressure vessels. This objective is to be accomplished by utilizing data from PISC-II round robin trials, modelling, and limited experimental work to supplement areas not adequately addressed by modelling or round robin trials. Work continued on addressing NRC comments on a draft report.

RPV Research. The objective of this subtask is to track work currently being performed under the PISC-III program; particularly work conducted under Actions 2 and 3. These actions provide uscful information concerning the capability to inspect nozales and dissimilar metal welds and will begin to address techniques for accurate flaw sizing as well as the reliability of vessel inspections. At this time, no results are available but these studies are expected to provide useful data bases and conclusions in the near future. Initial results will be made available to the PISC-1II Management Board in late 1991. In addition, a new activity was started to evaluate the status of the technology that the industry is developing for the inspection of the boiling water reactor (BWR) reactor pressure vessels. The major focus was on reviewing draft reports on Action 3.

NDE Requirements for Aging Plants. The ASME Section XI rules and procedures for flaw evaluation were examined under this subtask. The significant accomplishment was that it was concluded that the Code adequately considers the effects of embrittlement.

Equipment Interaction Matrix. The objective of this work is to evaluate the effects of frequency domain equipment interactions and determine tolerance values for improving ultrasonic inspection reliability. A computer model is being used 
to calculate flaw transfer functions and frequency domain effects that occur due to the interaction between inspection equipment and worst-case flaws. Calculated values are also being compared with experimental measurements to determine if other measurement-related effects, not programmed into the model, are significant enough for inclusion in the model.

During this reporting period, a status report was submitted for NRC publication and work continued on the validation of the model which considers component curvature.

\section{- New Inspection Criteria}

Work continued on assessments of the adequacy of existing ASME Code requirements for ISI and on developing technical bases for improved ISI requirements that will contribute to high nuclear power plant component structural integrity. Development of a comprehensive probabilistic approach for improved inspection requirements moved forward. A major focus of this effort has continued to be participation in an ASME Research Task Force on Risk-Based Inspection Guidelines. During this reporting period a second workshop on the expert elicitation process for the remaining five Surry 1 systems was held and structural reliability calculations using the PRAISE Code were begun.

- Consult on Field Problems

The objective of this work is to provide a rapid response to urgent and unexpected problems as they are identified by the Office of Nuclear Regulatory Research (RES). Efforts continued to support NRC staff in the application, validation, and modification of the VISA-II fracture mechanics code for predicting the contributions of undetected flaws to the failure of reactor pressure vessels under conditions of pressurized thermal shock accidents. Recent work to validate the VISA-II code revealed no significant errors, although some corrections were made to enhance the overall utility of this code. New features include modeling of residual stresses, modeling of underclad cracks, programming the chemistry factor, and improved plastic instability predictions. An updated version of the VISA-II code with documentation of all corrections and enhancements was prepared and made available to the NRC staff.

Worked with ORNL, EPRI, and others to benchmark the VISA-II Code with other fracture mechanics codes and then worked to understand the differences.

\section{- Piping Inspection Task}

This task is designed to address the NDT problems associated with piping used in light water reactors. The primary thrust of the work has been on wrought and cast stainless steel since these materials are harder to inspect than carbon steel. However, many of the subtasks' results also pertain to carbon steel. The current subtasks are: cast stainless steel inspection, surface roughness conditions, field pipe characterization, and PISCIII activities.

Cast Stainless Steel Inspection. The objective of this subtask is to evaluate the effectiveness and reliability of ultrasonic inspection techniques on LWR components containing cast stainless steel material. Far-side weld inspection is included in the scope of this work since the ultrasonic field passes through weld metal. Activities for this reporting period included an investigation of low frequency ultrasonic techniques inherently insensitive to macrostructural effects, a fracture mechanics evaluation aimed at estimating "critical" dimensions of circumferential cracks in CCSS primary pipe sections, and investigating the feasibility of implementing "adaptive ultrasonics" to the inspection of coarse grained materials.

Surface Roughness. The objective of this subtask is to quantify and develop requirements to limit the adverse effects of surface conditions upon an ultrasonic inspection. In order to foster collaboration between CNDE and PNL, Margaret Greenwood visited CNDE in December 1991 and had extensive discussions with Bruce Thompson, Ali Minachi, and Isaac Yalda about implementing the CNDE model at PNL. Extensive experiments were performed using the Brockman ( $\mathrm{x}-\mathrm{y})$ scanner. The ultrasound beam was directed toward 10, 30, and 60 mil steps and also with no step so that the 
beam was normal to the surface, produced a $45^{\circ}$ longitudinal wave in steel, and produced a $45^{\circ}$ shear wave in steel. C-scan images were obtained for these 12 cases. When a $45^{\circ}$ longitudinal wave is produced in stecl, it is also accompanied by a $21.7^{\circ}$ shear wave. A derivation, which assumed plane waves, showed that the longitudinal and shear waves should be separated in time by 2.9 microseconds. When a four-cycle tone burst was used, these two signals were seen on the oscilloscope and separated by the expected time. It is possible to obtain C-scans for both the longitudinal and shear signals. The latest model improvement at CNDE considers the propagation of ultrasound from the steel surface into the water, where the microprobe receives the signal, by including appropriate transmission coefficients. Much better agreement between theory and expeirmental data results.

Field Pipe Characterization. The objective of this subtask is to provide pipe weld specimens that can be used for studies to evaluate the effectiveness and reliability of ultrasonic inservice inspection (UT/ISI) performed on BWR piping. The five safe-ends removed from the Monticello nuclear power station are no longer needed for any programmatic work, and processes to dispose of these samples are under review to meet the new requirements for disposal required by state and federal agencies.
PISC III. This activity involves participation in the PISC-III program to ensure that the work addresses NDE reliability problems for materials and ISI practices on U.S. LWRs. This includes support for the co-leader of Action 4 on Austenitic Steel Tests (AST); providing a sector of the Hope Creek reactor pressure vessel containing two recirculation system inlet nozzles; coordination of the inspections to be conducted by U.S. teams on the various actions; input to the studies on reliability and specimens for use in the parametric, capability, and reliability studies of the AST. During this reporting period, the major effort was focused on the coordination of USA teams in the inspection of the wrought stainless steel capability specimens and identifying teams for setting up a schedule for the inspection of the cast-to-cast and the cast-towrought specimen sets. 


\section{Previous Reports in Series}

Doctor, S. R., A. A. Diaz, J. R. Friley, M. S. Good, M. S. Greenwood, P. G. Heasler, R. L. Hockey, R. J. Kurtz, F. A. Simonen, J. C. Spanner, T. T. Taylor, and T. V. Vo. 1992. Nondestructive Examination (NDE) Reliability for Inservice Inspection of Light Water Reactors. NUREG/CR-4469, PNL-5711, Vol. 14. Pacific Northwest Laboratory, Richland, Washington.

Green, E. R., S. R. Doctor, R. L. Hockey, and A. A. Diaz. 1992. Development of Equipment Parameter Tolerances for the Ultrasonic Inspection of Steel Components: Application to Components up to 3 Inches Thick. NUREG/CR-5817, Vol 1. Pacific Northwest Laboratory, Richland, Washington.

Doctor, S. R., M. S. Good, P. G. Heasler, R. L. Hockey, F. A. Simonen, J. C. Spanner, T. T. Taylor, and T. V. Vo. 1992. Nondestructive Examination (NDE) Reliability for Inservice Inspection of Light Water Reactors. NUREG/CR-4469, PNL-5711, Vol. 13. Pacific Northwest Laboratory, Richland, Washington.

Doctor, S. R., M. S. Good, P. G. Heasler, R. L. Hockey, F. A. Simonen, J. C. Spanner, T. T. Taylor, and T. V. Vo. 1992. Nondestructive Examination (NDE) Reliability for Inservice Inspection of Light Water Reactors. NUREG/CR-4469, PNL-5711, Vol. 12. Pacific Northwest Laboratory, Richland, Washington.

Doctor, S. R., M. S. Good, E. R. Green, P. G. Heasler, F. A. Simonen, J. C. Spanner, T. T. Taylor, and T. V. Vo. 1991. Nondestructive Examination (NDE) Reliability for Inservice Inspection of Light Water Reactors. NUREG/CR-4469, PNL-5711, Vol. 11. Pacific Northwest Laboratory, Richland, Washington.

Heasler, P. G., T. T. Taylor, J. C. Spanner, S. R. Doctor, and J. D. Deffenbaugh. 1990. Ultrasonic Inspection Reliability for Intergranular Stress Corrosion Cracks: $A$ Round Robin Study of the Effects of Personnel, Procedures, Equipment and Crack Characteristics. NUREG/CR-4908. Pacific Northwest Laboratory, Richland, Washington.

Spanner, J. C., S. R. Doctor, T. T. Taylor/PNL and J. Muscara/NRC. 1990. Qualification Process for Ultrasonic Testing in Nuclear Inservice Inspection Applications. NUREG/CR-4882, PNL-6179. Pacific Northwest Laboratory, Richland, Washington.
Doctor, S. R., J. D. Deffenbaugh, M. S. Good, E. R. Green, P. G. Heasler, F. A. Simonen, J. C. Spanner, T. T. Taylor, and T. V. Vo. 1990. Nondestructive Examination (NDE) Reliability for Inservice Inspection of Light Water Reactors. NUREG/CR-4469, PNL-5711, Vol. 10. Pacific Northwest Laboratory, Richland, Washington.

Doctor, S. R., J. D. Deffenbaugh, M. S. Good, E. R. Green, P. G. Heasler, F. A. Simonen, J. C. Spanner, and T. T. Taylor. 1989. Nondestructive Examination (NDE) Reliability for Inservice Inspection of Light Water Reactors. NUREG/CR-4469, PNL-5711, Vol. 9. Pacific Northwest Laboratory, Richland, Washington.

Doctor, S. R., J. D. Deffenbaugh, M. S. Good, E. R. Green, P. G. Heasler, F. A. Simonen, J. C. Spanner, and T. T. Taylor. 1989. Nondestructive Examination (NDE) Reliability for Inservice Inspection of Light Water Reactors. NUREG/CR-4469, PNL-5711, Vol. 8. Pacific Northwest Laboratory, Richland, Washington.

Doctor, S. R., J. D. Deffenbaugh, M. S. Good, E. R. Green, P. G. Heasler, F. A. Simonen, J. C. Spanner, and T. T. Taylor. 1988. Nondestructive Examination (NDE) Reliability for Inservice Inspection of Light Water Reactors. NUREG/CR-4469, PNL-5711, Vol. 7. Pacific Northwest Laboratory, Richland, Washington.

Doctor, S. R., J. D. Deffenbaugh, M. S. Good, E. R. Green, P. G. Heasler, G. A. Mart, F. A. Simonen, J. C. Spanner, T. T. Taylor, and L. G. Van Fleet. 1987. Nondestructive Examination (NDE) Reliability for Inservice Inspection of Light Water Reactors. NUREG/CR4469, PNL-5711, Vol. 6. Pacific Northwest Laboratory, Richland, Washington.

Doctor, S. R., D. J. Bates, J. D. Deffenbaugh, M. S. Good, P. G. Heasler, G. A. Mart, F. A. Simonen, J. C. Spanner, T. T. Taylor, and L. G. Van Fleet. 1987. Nondestructive Examination (NDE) Reliability for Inservice Inspection of Light Water Reactors. NUREG/CR4469, PNL-5711, Vol. 5. Pacific Northwest Laboratory, Richland, Washington.

Doctor, S. R., D. J. Bates, J. D. Deffenbaugh, M. S. Good, P. G. Heasler, G. A. Mart, F. A. Simonen, J. C. Spanner, A. S. Tabatabai, T. T. Taylor, and L. G. Van Fleet. 1987. Nondestructive Examination (NDE) Reli- 
ability for Inservice Inspection of Light Water Reactors. NUREG/CR-4469, PNL-5711, Vol. 4. Pacific Northwest Laboratory, Richland, Washington.

Collins, H. D. and R. P. Gribble. 1986. Siamese Imaging Technique for Quasi-Vertical Type (QVT) Defects in Nuclear Reactor Piping. NUREG/CR-4472, PNL-5717. Pacific Northwest Laboratory, Richland, Washington.

Doctor, S. R., D. J. Bates, R. L. Bickford, L. A. Charlot, J. D. Deffenbaugh, M. S. Good, P. G. Heasler, G. A. Mart, F. A. Simonen, J. C. Spanner, A. S.

Tabatabai, T. T. Taylor, and L. G. Van Fleet. 1986. Nondestructive Examination (NDE) Reliability for Inservice Inspection of Light Water Reactors. NUREG/CR4469, PNL-5711, Vol. 3. Pacific Northwest Laboratory, Richland, Washington.

Doctor, S. R., D. J. Bates, L. A. Charlot, M. S. Good, H. R. Hartzog, P. G. Heasler, G. A. Mart, F. A. Simonen, J. C. Spanner, A. S. Tabatabai, and T. T. Taylor. 1986. Evaluation and Improvement of NDE Reliability for Inservice Inspection of Light Water Reactors. NUREG/CR-4469, PNL-5711, Vol. 2. Pacific Northwest Laboratory, Richland, Washington.

Doctor, S. R., D. J. Bates, L. A. Charlot, H. D. Collins, M. S. Good, H. R. Hartzog, P. G. Heasler, G. A. Mart, F. A. Simonen, J. C. Spanner, and T. T. Taylor. 1986. Integration of Nondestructive Examination (NDE) Reliability and Fracture Mechanics, Semi-Annual Report, April 1984 - September 1984. NUREG/CR-4469, PNL5711, Vol. 1. Pacific Northwest Laboratory, Richland, Washington.

Good, M. S. and L. G. Van Fleet. 1986. Status of Activities for Inspecting Weld Overlaid Pipe Joints. NUREG/CR-4484, PNL-5729. Pacific Northwest Laboratory, Richland, Washington.

Heasler, P. G., D. J. Bates, T. T. Taylor, and S. R. Doctor. 1986. Performance Demonstration Tests for Detection of Intergranular Stress Corrosion Cracking. NUREG/CR-4464, PNL-5705, Pacific Northwest Laboratory, Richland, Washington.

Simonen, F. A. 1984. The Impact of Nondestructive Examination Unreliability on Pressure Vessel Fracture
Predictions. NUREG/CR-3743, PNL-5062. Pacific Northwest Laboratory, Richland, Washington.

Simonen, F. A. and H. H. Woo. 1984. Analyses of the Impact of Inservice Inspection Using Piping Reliability Model. NUREG/CR-3753, PNL-50\%. Pacific Northwest Laboratory, Richland, Washington.

Taylor, T. T. 1984. An Evaluation of Manual Ultrasonic Inspection of Cast Stainless Steel Piping.

NUREG/CR-3753, PNL-5070. Pacific Northwest Laboratory, Richland, Washington.

Bush, S. H. 1983. Reliability of Nondestructive Examination, Volumes I, II, and III. NUREG/CR-3110-1, -2, and -3; PNL-4584. Pacific Northwest Laboratory, Richland, Washington.

Simonen, F. A. and C. W. Goodrich. 1983. Parametric Calculations of Fatigue Crack Growth in Piping.

NUREG/CR-3059, PNL-4537. Pacific Northwest Laboratory, Richland, Washington.

Simonen, F. A., M. E. Mayfield, T. P. Forte, and D. Jones. 1983. Crack Growth Evaluation for Small Cracks in Reactor-Coolant Piping. NUREG/CR-3176, PNL-4642. Pacific Northwest Laboratory, Richland, Washington.

Taylor, T. T., S. L. Crau ford, S. R. Doctor, and G. J. Posakony. 1983. Detection of Small-Sized Near-Surface Under-Clad Cracks for Reactor Pressure Vessels.

NUREG/CR-2878, PNL-4373. Pacific Northwest Laboratory, Richland, Washington.

Busse, L. J., F. L. Becker, R. E. Bowey, S. R. Doctor, R. P. Gribble, and G. J. Posakony. 1982. Characterization Methods for Ultrasonic Test Systems.

NUREG/CR-2264, PNL-4215. Pacific Northwest Laboratory, Richland, Washington.

Morris, C. J. and F. L. Becker. 1982. State-of-Practice Review of Ultrasonic In-service Inspection of Class I System Piping in Commercial Nuclear Power Plants. NUREG/CR-2468, PNL-4026. Pacific Northwest Laboratory, Richland, Washington.

Becker, F. L., S. R. Doctor, P. G. Heasler, C. J. Morris, S. G. Pitman, G. P. Sclby, and F. A. Simonen. 1981. 
Integration of NDE Reliability and Fracture Mechanics, Phase I Report. NUREG/CR-1696-1, PNL-3469. Pacific Northwest Laboratory, Richland, Washington.

Taylor, T. T. and G. P. Selby. 1981. Evaluation of ASME Section XI Reference Level Sensitivity for Initiation of Ultrasonic Inspection Examination.

NUREG/CR-1957, PNL-3692. Pacific Northwest Laboratory, Richland, Washington. 


\subsection{Introduction}

The Evaluation and Improvement of NDE Reliability for Inservice Inspection of Light Water Reactors (NDE Reliability) Program at Pacific Northwest Laboratory (PNL) was established to determine the reliability of current inservice inspection (ISI) techniques and to develop recommendations that would ensure a suitably high inspection reliability if fully implemented. The objectives of this program for the Nuclear Regulatory Commission (NRC) are:

- Determine the reliability of ultrasonic ISI performed on commercial lightwater reactor (LWR) primary systems.

- Use probabilistic fracture mechanics analysis to determine the impact of NDE unreliability on system safety and determine the level of inspection reliability required to insure a suitably low failure probability.

- Evaluate the degree of reliability improvement that could be achieved using improved and advanced NDE techniques.
- Based on material propertics, service conditions, and NDE uncertainties, formulate recommended revisions to Section XI of the Regulatory and ASME Code requirements needed to ensure suitably low failure probabilities.

The scope of this program is limited to ISI of primary coolant systems, but the results and recommendations are also applicable to Class 2 piping systems.

This report is divided into the following sections. ,

- ASME Code Related Activitics

- Pressure Vessel Inspection

- New Inspection Criteria

- Consult on Ficld Problems

- Piping Task Activities 


\subsection{ASME Code Related Activities}

\subsection{Summary}

Participation in ASME Section XI and V activities continued toward achicving Code acceptance of NRCfunded PNL. research results to improve the reliability of nondestructive examination/inservice inspection (NDE/ISI). Minutes of the ASME Section XI Subgroup on Nondestructive Examination (SGNDE) meetings held August 1991 in Pittsburgh, PA and November 1991 in Anaheim, CA werc prepared, finalized, and distributed. Minutes for the SGNDE meeting held February 1992 in Atlanta, GA were drafted and assembled with attachments. Meetings of the Section V Subgroups on Ultrasonic Testing (SGUT) and on Acoustic Emission (SGAE) were atterded during ASME Section V meetings held in November 1991 in Anaheim, CA.

A special ultrasonic test block was designed, fabricated, and cvaluated for incorporation into the T-435 requirements for evaluating the lateral and depth resolution of SAFT-type UT systems. The SGUT approved revisions to the PNL-proposed T-435 document on "Computerized Imaging Techniques," and this document was then sequentially approved by the Section V Subcommittee and the ASME Main Committee (M.C.). During the November SGNDE meeting, the SC-XI Chairman announced that the Special Working Group on Eddy Current Testing (SWGET) had been discharged effective 11/18/91. Rules for ET examination of non-ferromagnetic heat exchanger tubing that have previously been published in Section XI were adopted for publication in Section V, and the relevant Section XI text (Appendix IV) will be deleted. A PNL-proposed revision to Appendix VIII regarding UT equipment characterization requirements, and a Code Case to clarify rules for limited certification of NDE personnel, both received final approval from the Board on Nuclear Codes and Standards (BNCS). The new ASNT PQ standard (ASNT-CP-189) was approved by both the SGNDE and the SC-XI Subcommittee.

\subsection{Introduction}

The objective of this task is to develop and/or evaluate new criteria and requirements for qualifying ultrasonic testing/inservice inspection (UT/ISI) and other NDE/ISI systems. The ultimate goal is for these crite- ria and requirements to be incorporated into Sections $\mathrm{V}$ and XI (SC-V and SC-XI) of the ASME Boiler and Pressure Vessel Code (ASME Code). If that goal cannot be met, or if the requirements adopted by the ASME Code are inadequate, PNL may also be requested to prepare draft Regulatory Guide input as a backup approach.

To implement this goal, PNL staff members are active participants in Section XI and Section V ASME Code committee activities. PNL staff members serve as secretary of the SC-XI SGNDE, chair a SC-V task group to develop acoustic emission requirements, and serve as members of the SC-XI Working Group on Surface Examination and Personnel Qualification (WGS) and the SC-XI Working Group on Volumetric Examination and Procedure Qualification (WG-V). In addition, PNL personnel serve as members of the SC-V Subgroup on Ultrasonic Testing (SGUT) and the SC.V Subgroup on Acoustic Emission (SGAE). Administrative assistance is also provided in support of related efforts to achicve ASME Code acceptance of new personnel qualification (PQ) and performance demonstration (PD) requirements for eddy current equipment operators and data analysts, adoption of U.S. National Standard requirements for personnel qualification, and a the SC-V activity to develop requirements and criteria for computerized UT imaging techniques.

\subsection{Status of Work Performed}

Proactive participation of PNL personnel in ASME Code activities continued toward achieving Code acceptance of NRC-funded PNL research results to improve the reliability of NDE/ISI. During this reporting period, meetings of the ASME Section XI Subcommittee (including relevant Subgroup and Working Group meetings) were attended November 18-21, 1991 in Anaheim, CA, and February 10-13, 1992 in Atlanta, GA. In addition, meetings of the Section V Subcommittee on Nondestructive Examination (specifically the Subgroup on Ultrasonic Testing and the Subgroup on Acoustic Emission) were attended November 18-21, 1991 in Anaheim, CA (joint Code Committee meeting). The February 1992 meeting in New York City, NY was not attended due to a conflict although a representative was designated. Agendas and minutes of the SGNDE meetings held 
in conjunction with the Section XI Subcommittee meetings were prepared and distributed.

A special ultrasonic test block was designed, fabricated, and evaluated. The purpose of this mild stecl test block is to evaluate the lateral and depth resolution of SAFTtype UT systems. The key design features of this block were incorporated into the proposed T-435 document on "Computerized Imaging Techniques" along with specific calibration requirements for SAFT-type computerized UT imaging systems. These proposed new Section $\mathrm{V}$ requirements were then approved by the SGU', the SC-V Subcommittee on NDE, and the ASME Main Committee (M.C.). In March 1992, PNL was advised that the proposed T-435 requirements had received formal (i.c., letter ballot) M.C. approval and been submitted for letter ballot by the Board on Pressure Vessel Technology (BPVT). Assuming prompt approval by the BPVT, this document will be published in the 1992 Code addenda, which will constitute formal ASME Code acceptance of the SAFT technology.

During the November 1991 SGNDE meeting, the SCXI Chairman announced that the Special Working Group on Eddy Current Testing (SWGET) had been discharged effective $11 / 18 / 91$. The reasons for this action included polarization of views, lack of progress due to technical obstacles, NRC concerns, etc. The performance demonstration requirements developed by the SWGET to date will be provided to the WG-S in its current (draft) form.

Two new Section XI Code Cases on MT and ET examination of coated ferritic materials (e.g., containment vessel surfaces) were adopted as Mandatory Appendices to Section V, Articles 7 and 8, respectively. Previously developed Section XI rules for ET examination of nonferromagnetic heat exchanger tubing have now been adopted for publication in Section $\mathrm{V}$, and the relevant Section XI text (i.e., Appendix IV) will now be deleted.

The ASME M.C. Task Group on PQ Requirements for NDE Fersonnel completed its task and provided recommendations to the M.C. Chairman. This task group recommended that the ASME Code continue to reference the 1984 Edition of SNT-TC-1A, and that Sections III and XI should be permitted to impose supplemental, additional requirements and/or PQ references as needed. This group did not recommend adoption of the 1988 Edition of SNT-TC-1A, which is consistent with the position taken by the PNL representative over the past three years. A related action occurred in February 1992 when both the SGNDE and the SC-XI Subcommittee formally approved adoption of the recently issucd ASNT Standard on Personnel Qualification (ASNT-CP-189).

A PNL-proposed revision to Appendix VIII, regarding UT equipment characterization requirements, received final (letter ballot) approval by the ASME Board on Nuclear Codes and Standards (BNCS). This document will be published in the 1992 Addenda to Section XI. A Code Case to clarify the rules for limited certification of NDE personnel also received final BNCS approval.

Work was initiated on a new task to draft a proposed new Section V, Article 13 on "Continuous Acoustic Emission Monitoring of Pressure Vessels." A detailed outline has been developed and refined, and draft text has been prepared for some of the initial sections of this document. When completed, this Article will provide a generic set of requirements for inservice monitoring of pressure vessels, and a series of Mandatory Appendices will be included to address a) nuclear vessels, b) leak detection applications, c) high-temperature applications, d) limited zone monitoring, and e) nonmetallic vessels.

\subsection{Future Work}

Minutes for the ASME Section XI SGNDE meeting held February 1992 in Atlanta, GA will be finalized for distribution to the approximately 65 recipients. Administrative support will continue for the activity to develop requirements for computerized UT imaging systems and a response will be prepared for any negatives arising from the BNCS ballot. Development of Article 13 on "Continuous AE Monitoring of Pressure Vessels" will continue.

Agendas and minutes will be prepared 4-6 weeks prior to each Section XI mecting. Future Section XI meetings will be held May 1992 in San Antonio, TX (joint Code Committee meeting), August 1992 in Chicago, $\mathrm{L}$, and December 1992 in Louisville, KY (joint Code Committe meeting). 


\subsection{Pressure Vessel Inspection}

\subsection{Pressure Vessel Inspection}

\subsubsection{Summary}

The objective of this task is to determine the capability of U.S. ultrasonic inservice inspection of reactor pressure vessels. This objective is to be accomplished by utilizing data from PISC-II round robin trials, modelling and limited experimental work to supplement areas not adequately addressed by modelling or round robin trials. Additional comments have been received from the draft report on the re-analysis of the PISC-II data, and these comments are being addressed. A final version of this report will be submitted to the NRC program manager.

\subsubsection{Introduction}

The pressure vessel inspection task is divided into three subtasks which are:

- PISC II Re-analysis - The effort in this task is a re-analysis of data using statistically based techniques gathered during the PISC-II round robin trials. Ultrasonic inspection data was gathered on four heavy section steel components which included two plates and two nozzles configurations. A total of $\mathbf{4 5}$ teams from the Common Market, Japan, and the United States participated in the round robins.

- RPV Research - The focus of this activity is to track the work being performed under the PISC III program. This is intended to ensure that the PISC III work of the Action 2 on Full Scale Vessel Tests (FSV) and the Action 3 on Nozzles and Dissimilar Metal Welds provides useful information for conditions and practices in the USA. This subtask will also track the PISC III work and relay points of interest and concern to the NRC that may arise from the analysis of the newly created and evolving data base. In addition, a new activity was started to evaluate the status of the technology that the industry is developing for the inspection of the boiling water reactor (BWR) reactor pressure vessels. During this reporting period the work focused on the review of PISC-III draft reports.
- NDE Requirements for Aging Plants - The NDE Requirements for Aging Plants Task was initiated in April 1991. The objective of this task is to determine if special inservice inspection (ISI) requirements are needed to address aging in nuclear power plants. Initial efforts have focussed on reviewing the technical bases for existing reactor pressure vessel (RPV) flaw acceptance criteria. The RPV was selected for initial study since it was judged to be the most important component unlikely to be replaced and is the one component most susceptible to radiation damage.

\subsubsection{Status of Work Performed}

A summary of the work performed for each subtask is provided below.

\subsubsection{PISC II Re-analysis}

A summary of the analysis was provided in semi-annual report NUREG/CK-4469, Vol. 11. The work performed during this time period, began addressing the NRC comments on the draft report.

\subsubsection{RPV Research}

The objective of this work is to track the work that is currently being performed under the PISC III program. Of particular interest is the work being conducted in Actions 2 and 3. These actions will provide useful information concerning the capability to inspect nozzles and dissimilar metal welds and begin to address some aspects of the ability of advanced techniques to accuratcly size flaws and some aspects of the reliability to inspect actual vessels. At this time, there are no results available because the studies cannot be released until the PISC-III management board approves them formally.

Based on the results and data bases from the PISC III program, deficiencies will be identified and a program to provide the necessary supplemental information will be developed and implemented. At this time, this subtask is focused on tracking the relevant PISC III program activities and the results being developed. This has involved reviewing some initial draft reports on some of the studies, but even these will change since the reports are not based on destructive data. 


\subsubsection{NDE Requirements for Aging Plants}

Study of Section XI IWB-3400 continued with special focus on PWR beltline applicability. Spence Bush, PNL, was most helpful in explaining some of the subtleties of the Code. It was concluded that the Code adequately considers the effects of embrittlement - mainly clue to the "maximum postulated defect" clause of Subsection IWB-3410.1, paragraph $b$.

\subsubsection{Future Work}

- PISC II Re-analysis - The NRC comments received on the early draft will be accommodated, and a final version of this report will be submitted to the NRC for publication.

- RPV Research - The work planned for the next reporting period will continue to focus on reviewing PISC-III documents and begin drafting a status report on the technology available for inspecting BWR RPVs.

- NDE Requirements for Aging Plants - The response of vessels having "Section XI acceptable" flaws to pressurized thermal shock loading will be studied. This will be done by using the VISA Code.

\subsection{Equipment Interaction Matrix}

\subsubsection{Summary}

The objective of this work is to determine how an ultrasonic inservice inspection is affected when the performance of one of the components is changed. It is necessary to ensure that equipment interaction effects do not lead to reduced inspection reliability. Specifically, we need to quantify the equipment interaction effects so that ASME Code requirements can be established to ensure that reliable inspection does indeed occur. The report that details the prior research toward that goal is entitled The Interaction Matrix Study: Models and Equipment Sensitivity Studies for the Ultrasonic Inspection of Thin Wall Steel and was written by E. R. Green, S. R. Doctor, R. L. Hockey, and A. A. Diaz. This report has been published as NUREG/CR-
5817. The Code recommendations that resulted from this research have been adopted. The goal of the current research is to determine if any changes are needed in the Code requirements for inspections being conducted on curved surfaces. The following computer codes are now running on the SUN Workstation: TOTAL, TOTALR, and CURVE. Additional computer code improvements have been made to automate some of the operations, especially in searching for worst-case defects. The validity of code CURVE has been tested by comparing the output for a case with a very large radius with that from code TOTAL for a flat surfacc. The excellent agreement is an indication that there are no coding errors, but the experimental validation of code CURVE remains to be completed.

\subsubsection{Introduction}

The goal of this work is io define operating tolerance requirements for UT/ISI equipment that limit the effects of frequency domain interactions, thus, improving ISI reliability.

Much research has been completed toward reaching this goal and it is described in a report, NUREG/CR5817. ASME Code recommendations were developed as a result and they have been adopted. The second phase remains to be completed and that part deals with performing the same kind of analysis for circular surfaces that has been performed for flat surfaces.

\subsubsection{Status of Work Performed}

The report The Interaction Matrix Study: Models and Equipment Sensitivity Studies for the Ultrasonic Inspection of Thin Wall Steel written by E. R. Green, S. R. Doctor, R. L. Hockey, and A. A. Diaz has been published as NUREG/CR-5817. This report details the research that was needed to make recommendations for the ASME Section XI Code, Appendix VIII. This research showed that the Code bandwidth equipment tolerance of $10 \%$ was sufficient to ensure $2 \mathrm{~dB}$ signal amplitude repeatability. Also, it was recommended that the Code center frequency requirement of $\pm 20 \%$ be changed to the following: a) a center frequency tolerance of $\pm 5 \%$ for systems with bandwidths less than $30 \%$ b) a tolerance of $\pm 10 \%$ for systems with bandwidths greater than $30 \%$. These have been adopted into the ASME Section XI Code. 
The Code requirements for flat surfaces have just been described. The goal of the current research is to determine if there would be any changes in the Code recommendations for curved surfaces. Such information would be necessary for ISI/UT of nozzles and pressure vessels.

The following computer codes, originally running on a VAX $11 / 780$, have been transferred to a SUN Workstation: TOTAL, TOTALR (faster version of TOTAL), and CURVE. Test cases have been run on the SUN and compared with output from the VAX 11/780 and the agreement between them is very good.

Some computer code improvements have been made to automate some of the operations: 1) Often there are two possible paths for the rays. Either a ray will be reflected from the bottom surface, then from the crack, and finally strike the receiving transducer or it will hit the crack first and then be reflected from the bottom. Code TOTAL must be run for each case and then combined; a short computer code was written to perform this summation. 2) In order to improve the documentation, input parameters are written at the beginning of each output file. 3) TOTALR was automated to systematically search for worst-case defects in the acoustic system (WCDAS) by determining the frequency at which a minimum occurred in the transfer function in the vicinity of $2.25 \mathrm{MHz}$ and also determining the slope of the transfer function in the vicinity of 2.25 $\mathrm{MHz}$. The calculation was carried out for 10 different crack angles. The printout gave the frequency for the minimum and the slope for each crack angle. In this way one can choose cases of interest and it is an efficient way to search for WCDAS.
Ed Green made modifications of code TOTAL so that it could treat circular surfaces and called this new code CURVE. In order to test the validity of his coding he compared the output from CURVE, for a case where the radius was 5 meters, to that from TOTAL and found excellent agreement. This is a good indication that there are no errors in the code. Experimental validation of CURVE is the next step.

\subsubsection{Future Work}

The following work remains to be completed:

- Experimental validation of code CURVE. This will be accomplished by performing pulse-echo experiments with circular sections with the ends cut at different angles.

- Compare results with calculations from CURVE

- Scarch for WCDAS

- Experimentally validate some WCDAS

- Develop appropriate ASME Code recommendations, if needed 


\subsection{New Inspection Criteria Task}

\subsection{Summary}

Work continued on assessments of the adequacy of cxisting ASME Code requirements for ISI and on developing technical bases for improved ISI requirements that will assure high nuclear power plant component structural integrity. Development of a comprehensive probabilistic approach for improved inspection requirements moved forward. A major focus of this effort has continued to be participation in an ASME Ru. .earch Task Force on Risk-Based Inspection Guidelines. During this reporting period the ASME Task Force completed final revisions to a document specifically directed to light water reactor nuclear power plant components "Risk-Based Inspection - Development of Guidelines - Volume 2 - Part 1 - Light Water Reactor (LWR) Nuclear Power Plant Components". Publication as an ASME report is scheduled for June 1992.

Calculations have applied probabilistic risk assessment (PRA) to cstablish inspection priorities for pressure boundary systems and components. Plant-specific riskbased studies have been for the Surry Unit 1 Nuclear Power Station, with the cooperation of Virginia Electric Power Company. During this reporting period a final ranking of components and associated sensitivity calculations for four critical systems (reactor pressure vessel, reactor coolant system, low pressure injection system and auxiliary feedwater system) were completed. Ranking of components in the remaining Surry-1 systems continued with an expert elicitation in February 1992 to estimate component rupture probabilities.

Improved strategies for inspecting the highly ranked piping and vessel components are being developed in collaboration with members of the ASME Research Task Force. Structural reliability calculations have begun through applications of the PRAISE code to predict leak and rupture probabilities and the effects of alternative inspection scenarios on these probabilities.

\subsection{Introduction}

This task is directed to the development of improved inservice inspection (ISI) criteria using risk-based methods, with the long-range goal to propose changes for consideration by ASME Section XI. These improved criteria will help to establish priorities for selecting systems, components and structural elements for inspection, and will help to determine the extent, frequency, and method of examination. The objective is to ensure that ISI programs ensure a suitably low failure probability, and thus contribute in an effective manner to safe nuclear power plant operation.

In past work, we have reviewed and evaluated various concepts for probabilistic inspection criteria, and have interacted with other industry efforts, notably through the ASME Research Task Force on Risk-Based Inspection Guidelines. During FY89 we completed pilot applications of PRA methods to the inspection of piping, vessels, and related components for a sample of eight representative nuclear power plants (Surry-1, Zion-1, Sequoyah-1, Ocones-3, Crystal River-3, Calvert Cliffs-1, Peach Bottom-2 and Grand Gulf-1). An overview of the results of this study can be found in Vo, et. al. 1990. In summary, the results provided generic insights that could be extrapolated from the eight plants to specific classes of light water reactors. With a few exceptions, the PRA-based priorities for inspection of systems were generally correlated with current ASME Section XI requirements for Class 1, 2, and 3 systems.

Starting in FY90 our work has addressed inspection priorities at a more detailed component level, and focused on plant-specific calculations for the Surry Unit 1 Nuclear Power Station. During this reporting period we continued with the Surry-1 studies by documenting evaluations for the initial four systems, and have begun work on the remaining systems. Future results will give a complete picture of the most risk significant components within the plant, and will identify inspection strategies that can ensure component failure probabilities which meet target risk goals.

\subsection{Status of Work Performed}

\subsubsection{ASME Task Force on Risk-Based In- spection Guidelines}

During this reporting period we have continued to develop approaches for risk-based inspection requirements. Activities in this area have involved Pacific Northwest Laboratory (PNL) participation on a special ASME Rescarch Task Force on Risk-Based Inspection Guidelines, with Dr. F. A. Simonen and Dr. B. F. Gore 
and Mr. T. V. Vo serving as members of the Task Force. The ASME group has been identified by PNL as an effective route to achicve long-range goals for improved inspection criteria. Recently the Task Force has expanded its efforts related to other industrics (fossil power and petroicum) and is preparing documents that recommend specific approaches to riskbased inspection for these industries. Nevertheless, there is a strong and continuing effort on nuclear power applications, with the goal to develop recommendations to ASME Section XI on the use of risk-based methods to develop improved inspection programs.

There was only one formal meeting of the ASME Research Task Force during this reporting period on November 20-21 at Anaheim, California, but several other informal meetings of individual task force members have focused solely on nuclear power activities. A meeting on February 7, 1992 in Washington D.C. developed an outline for the Volume 2 - Part 2 document on nuclear power applications. This outline identified future work needed to develop inspection strategies and to perform structural reliability calculations. A working session on March 24, 1992 at Rockville, Maryland completed a table of inspection strategies for reactor pressure vessels and began work on inspection strategies for piping in the low pressure injection system.

Members (Sub ommittee on Metal Components) of the NRC Advisory Committec on Reactor Safeguards (ACRS) were given a detailed bricfing on February 13, 1992 at Bethesda, Maryland that covered activities in the area of risk-based inspection both at PNL and by the ASME Research Task Force. Other presentations during this reporting period were made to the ASME Section XI Working Group on Long Range Planning and the ASME Section XI Subgroup on Core Support and Internal Structures.

During this reporting period we continued to work with the ASME Task Force to complete final revisions to the first document specifically directed to light water reactor nuclear power plant components "Risk-Based Inspection - Development of Guidelines - Volume 2 Part 1 - Light Water Reactor (LWR) Nuclear Power Plant Components." This document recommends and describes specific methods to be used in developing risk-based inspection plans for nuclear power facilities.
Publication as an ASME report is scheduled for June 1992.

Future efforts of the ASME Rescarch Task Force will apply the recommended risk-based methodologies to develop improved inspection programs for nuclear power plant components (Volume 2 - Part 2). Results of calculations performed on the new criteria task will be a major contribution to the Part 2 Document. This document is scheduled for publication in the later p.ut of 1993, and will make specific recommendations for consideration by ASME Section XI.

\subsubsection{Plant Specific PRA Application to Surry-1}

A major part of the new inspection criteria task involves the application of existing probabilistic risk assessments (PRA) to establish inspection priorities for pressure boundary systems and components. During this reporting period a pilot application of PRA methods to the Surry-1 plant continued.

The Surry-1 work has applied a methodology (Vo, et al. 1989) that uses the results of PRA's in combination with the techniques of failure modes and effects analysis (FMEA) to identify and prioritize the most risk-important systems and components at nuclear power plants. The specific systems initially selected for analysis were the reactor pressure vessel, the reactor coolant, the low pressure injection (including the accumulators) and the auxiliary feedwater. The risk-based rat king of components within these four systems was conıpleted during the previous reporting period, and results were described in the previous semi-annual report of this series. A draft report has since been prepared to document these results in detail and to describe recently completed sensitivity studies. These sensitivity studies have addressed the risk contributions of indirect consequences of pipe ruptures and the uncertainties in estimates of component rupture frequencies. It has been established that indirect contributions to core damage frequency from component failures in the four systems of interest (c.g., contributions due to pipe whip, jet impingement effects, failures of vital electrical buses, etc.) were negligible (less than $2 \%$ ). 
Efforts during this reporting period have been expanded to address the other remaining systems at Surry-1 (high pressure injection, main feedwater, scrvice water, component cooling water, main steam, condensaic, and residual heat removal systems). Staff from the Virginia Electric Power Company (VEPCO) have continued to participate in the pilot study, and have thereby assured that the plant models are as realistic as possible and reflect plant operational practices. The highlight of the Surry-1 study during this reporting period was an expert elicitation workshop on comr 1 rupture probabilities held on February 3-6, 1992 in w a sington DC. The planning and accomplishments of this workshop are desc, ibed below.

Future work will result in a comprehensive ranking of all the most important components within the Surry-1 plant systems. These risk-based priorities will permit evaluation of current inservice inspection requirements as specitied by Section XI of the American Society of Mecha vical Engineers Code. The objective is to identify needed improvements to current ISI plans. These results will be made available to the ASME Research Task Force as recommendations for consideration by ASME Section XI.

\subsubsection{Expert Judgement Elicitation for Rup- ture Probabilities}

The risk-based studies of the Surry-1 plant have required estimates of rupture probabilities on a detailed component-by-component level. Because neither sufficient data from operating experience nor detailed fracture mechanics analyses are available, the expert judgment elicitation process has been selected as a method to estimate needed rupture probabilities.

PNL conducted the first of two expert judgment elicitation meetings on May 8-10, 1990 at Rockville, Maryland to address the issue of failure probabilities for Surry-1 components. The systems addressed by the first elicitation were the reactor pressure vessel, reactor coolant, low pressure injection (including the accumulators), and auxiliary feedwater. During this reporting period a second workshop was held on February 3-6, 1992 in Washington DC to address Surry-1 components for the high pressure injection system, the residual heat removal system, the component cooling water system, the service water system and the power conversion system.

The second expert elicitation again used a systematic procedure, which closely followed the approach used for the NUREG-1150 PRAs (NRC 1990 and Wheeler, et al. 1989). The invited participants as listed in Table 4.1 were chosen from the nuclear industry (utilities and vendors), the NRC, National Laboratories, and academia. A spectrum of interests were represented to cover many areas including reactor systems, materials and structural integrity, operational experience, inspection and repair of reactor systems, and PRA. Prior to the elicitation meeting, PNL sent reference materials to the experts including system descriptions, data sources, models and recent PRA results.

The first day of the workshop was devoted to training. This training was to help the experts become better able to encode their knowledge and judgements into a numerical format that could be incorporated into PNL risk models. Presentations also sensitized the experts to potential biases that might be experienced in this type of meeting. Other presentations including of a summary of historical data on piping ruptures experienced in the nuclear power industry.

For each system there was a discussion period whereby the experts were encouraged to share information on plant design, operating practices, failure histories, material degradation mechanisms and inspection findings. Following this discussion each expert completed questionnaire forms that addressed location specific rupture probabilities for the systems and components of interest. There was no effort to seck a consensus among the experts. The elicited data (for a total of $345 \mathrm{com}$ ponents for the 5 systems addressed) included best estimates of probabilities, uncertainty ranges and an assessment of the effect of aging on the rupture probabilitics. In the next reporting period, PNL will statistically combine the data from the individual judgements to obtain a single composite judgement for the rupture probability of each component.

\subsubsection{Structural Reliability Calculations}

The long range objective of the new criteria task is to develop improved inservice inspection plans (what, 
where, when and by what method) using risk-based approaches. Following the guidelines given in the Volume 1 document issued by the ASME Research Task Force on Risk-Based Inspection, probabilistic fracture mechanics and decision risk analysis methods will be used by PNL in a cooperative effort with other members of the ASME Research Task Force to identify inspection strategies that meet criteria for both safety and cost effectiveness.

To prepare for probabilistic fracture mechanics calculations we have participated in a series of informal meetings with key members of the Research Task Force. These meetings have develr ped tables to define potential strategies for inspecting specific components. Table 4.2 illustrates the range of options under consideration for inspecting the reactor pressure vessel. A spectrum of strategies, including current industry practices, have been defined from combinations of these options. Structural reliability calculations will determine which of the identified strategies can meet goals of ensuring acceptable failure probabilities. Each of the acceptable strategies will be evaluated by the Research Task Foree using the methods of decision risk analysis to quantify costs/benefit considerations.

The PRAISE code for predicting leak and rupture probabilities has been obtained by PNL and has been applied in a preliminary set of sensitivity calculations. The PRAISE code predicts rupture and leak probabilities for reactor piping, and includes the effects of inservice inspection on piping reliability. In preparation for future calculations we are placing a subcontract with Failure Analysis Associates (the developer of the PRAISE code) for specialized training and guidance in the application of the code to model the failure of structural components and the potential reductions in failure rates achievable by inservice inspection. Unexpected delays caused by subcontracting procedures have been encountered, and work w' a Failure Analysis Associates will not begin until the next reporting period.

In collaboration with Jerry Phillips at Idaho National Engineering Laboratory (INEL) we have performed a set of sensitivity calculations with the PRAISE code. These calculations make use of a model developed under NRC funding by INEL to simulate thermal fatigue in a segment of auxiliary feedwater system piping. Our calculations evaluated the effects of alternative inspection plans on the leak and rupture probabilitics predicted in the INEL study. The calculations also evaluated the sensitivity of these probabilities to inputs and assumptions to the model. Rupture probabilities were found to be very sensitive to the assumed initial length of the circumferential flaw. Increasing the initial flaw length had almost no effect on leak probabilities, but did very significantly increase the rupture probabilities by a factor of nearly 1000 . In future calculations uncertainties in flaw length will be given carelut consideration.

Table 4.3 summaries the results of calculations for some seven different inspection strategies beginning with a baseline case of no inspection. Both preservice and inservice inspection were evaluated. Each inservice inspection strategy was characterized by a probability of flaw detection (POD) curve and by the number of inservice inspections performed over the 48 year operating life of the component. Table 4.3 indicates some significant trends. Preservice inspection was found to very greatly reduce the calculated probability of failure, since the fracture mechanics model assumed that all failures are the result of initial fabrication flaws. Inservice inspections also reduced failure prohabilities. In this case of inservice inspection, the two POD curves (i.e., poor and good) were about equally effective. However, increasing the number of inspections over the operating life of the component from 3 to 15 did substantially reduce the predicted leak and rupture probabilities (by a factor of about 3 ).

\subsection{Future Work}

Future activities on the New Inspection Criteria Task will include:

- Continuing support of the ASME Research Task Force on Risk-Based Inspection Guidelines.

- Reduction of the data from the expert elicitation on rupture probabilities for the five remaining systems at Surry-1.

- Probabilistic fracture mechanics calculations to evaluate the effects of inservice inspection on the reliability of vessel and piping components. 
- Continue with the ISI prioritization for components at Surry-1. Visits to the Surry-1 plant will be concluded during the next reporting period.

Work on this task is proceeding at a somewhat slower pace than expected, due in part to reductions in available funding and higher than expected cost of the expert clicitation mecting. Kisk-based rankings of Surry-1 components will not be completed until next fiscal year.

The long range plan is to continue with pilot calculations and to use the results to focus inspections on the high risk components. Once the Surry-1 studics are complete, future work will evaluate a representative
BWR plant. Structural reliability calculations will continue and the results will be used in the development of risk-based inspection programs for the high priority components. As part of the inspection program development we will assign target values of rupture probabilitics that are to be maintained by inservice inspection. Working with the ASME Rescarch Task Force we will provide information for use in the decision risk analyses that will identify those inspection strategies that meet criteria for both safety and cost effectiveness. Output from the New Criteria Task will be made available to the ASME Rescarch Task Force on Risk-Based Inspection Cuidelines for their use in preparing a document that will recommend risk-based inspection programs for codes and standards consideration. 
Table 4.1. List of Expert Attendees at Rupture Probability Judgement Elicitation Workshop

\begin{tabular}{||l|l|l||}
\hline \multicolumn{1}{||}{ Name } & \multicolumn{1}{c||}{ Organization } & \multicolumn{1}{c||}{ Area of Expertise } \\
\hline EXPERT PANEL & Westinghouse Electric Corporation & Structures/Fracture Mechanics \\
\hline Bishop, Bruce & Rolls Royce \& Associates & Structures/PRA \\
\hline Chapman, Vic & University of Missouri-Rolla & PRA/Reactor Operation \\
\hline Edwards, Ray & Ohio State University & Materials/Structures \\
\hline Shewmon, Paul & Battelle Columbus Laboratory (retired) & Structures/Service Experience \\
\hline Rodabaugh, Everett & NUS Corporation & Failure Data Base \\
\hline Jamali, Kamiar & U.S. Nuclear Regulatory Commission & Structures/PRA \\
\hline O'Brien, John & Idaho National Engineering Laboratory & Reactor Systems/PRA \\
\hline Phillips, Jerry & Martin Marietta Encrgy Systems & ISI/Reactor Technology \\
\hline Pullins, Steve & U.S. Nuclear Regulatory Commission & Statistics/Expert Elicitation \\
\hline NORMATIVE/SUBSTANTIV EXPERTS & Decision Analysis \\
\hline Abramson, Lee & Westinghouse Electric Corporation & ISI/Plant System/Reactor Operation \\
\hline Perduc, Robert & Virginia Electric Power Corporation & Reactor System/PRA \\
\hline McNcil, Alex & Pacific Northwest Laboratory & Structures/Fracture Mechanics \\
\hline Gore, Bryan & Pacific Northwest Laboratory & Reactor System/PRA/Plant Aging \\
\hline Simonen, Fred & Pacific Northwest Laboratory & \\
\hline Vo, Troung &
\end{tabular}


Table 4.2. Pressurized Water Reactor Pressure Vessel Inspection Strategy

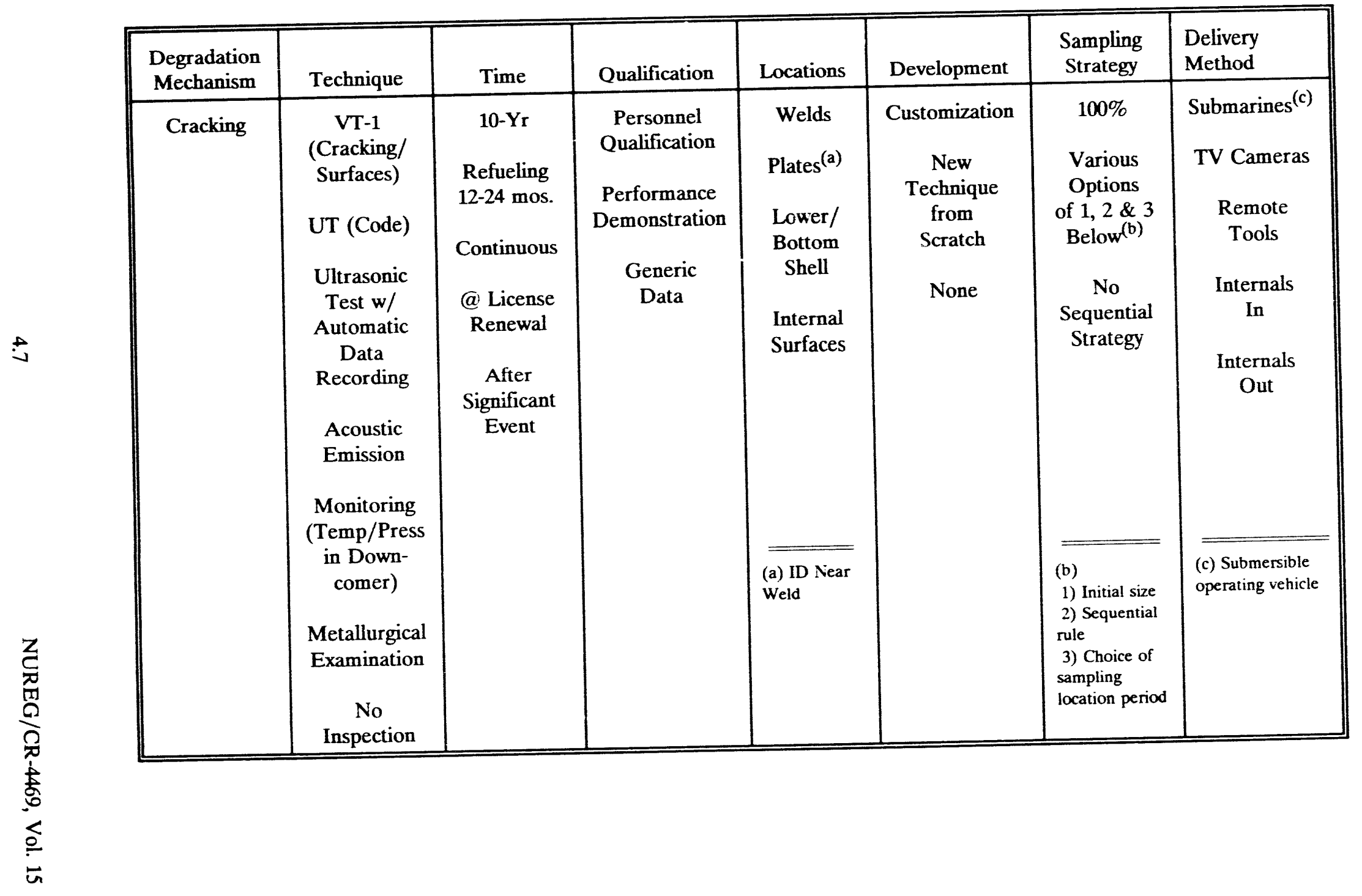


New Inspection Criteria

Table 4.3. Effect of Inspection on Thermal Fatigue in Auxiliary Feedwater Piping

\begin{tabular}{||l|l|l|l|l||}
\hline $\begin{array}{c}\text { POD } \\
\text { Preservice } \\
\text { Inspection }\end{array}$ & \multicolumn{1}{|c|}{$\begin{array}{c}\text { POD } \\
\text { Inservice } \\
\text { Inspection }\end{array}$} & $\begin{array}{c}\text { Number of } \\
\text { Inservice } \\
\text { Inspections }\end{array}$ & $\begin{array}{c}\text { Cumulative } \\
\text { Probability of } \\
\text { Leak at 48 Years }\end{array}$ & $\begin{array}{c}\text { Cumulative } \\
\text { Probability of } \\
\text { Break at 48 Years }\end{array}$ \\
\hline \hline None & None & None & $2.04 \mathrm{E}-02$ & $6.55 \mathrm{E}-05$ \\
\hline None & Poor & 3 & $1.22 \mathrm{E}-02$ & $3.69 \mathrm{E}-05$ \\
\hline None & Good & 3 & $1.21 \mathrm{E}-02$ & $3.65 \mathrm{E}-05$ \\
\hline None & Poor & 15 & $1.01 \mathrm{E}-02$ & $1.10 \mathrm{E}-05$ \\
\hline None & Good & 15 & $1.00 \mathrm{E}-02$ & $1.07 \mathrm{E}-05$ \\
\hline Good & None & None & $4.13 \mathrm{E}-12$ & $2.13 \mathrm{E}-17$ \\
\hline Good & Good & 15 & $1.38 \mathrm{E}-21$ & $1.46 \mathrm{E}-23$ \\
\hline
\end{tabular}

Poor POD $=50 \%$ POD at $a / t=50 \%$

Good POD $=50 \%$ POD at $a / t=10 \%$

$\mathrm{a}=$ flaw depth

$t=$ wall thickness 


\subsection{Consult on Field Problems}

\subsection{Summary}

Efforts continued to support NRC staff in the application, validation and modification of the VISA-II fracture mechanics code for predicting the contributions of undetected flaws to the failure of reactor pressure vessels under conditions of pressurized thermal shock accidents.

\subsection{Introduction}

This task is to provide on-call technical assistance to RES as the need may arise for NDE-related issues.

\subsection{Status of Work Performed}

\subsubsection{VISA-II Code}

We continued to support NRC staff in the application, validation and modification of the VISA-II fracture mechanics code. This code predicts the contributions of undetected flaws to the failure of reactor press re vessels under conditions of pressurized thermal shock accidents, and has been in use hy NRC staff and others for plant specific vessel evaluations.

During this reporting period a new version of the VISA-II code with documentation of all corrections and enhancements was made available to the NRC and to others as requested by the NRC project monitor. The updated version of the code is documented by a letter report to Mr. M. E. Mayfield of the NRC dated October 7, 1991. Copies of the code were distributed to Westinghouse Electric, Babcock and Wilcox Nuclear Services and Baltimore Gas and Electric.

We worked with Terry Dickson at Oak Ridge National Laboratory in a review of code capabilities to predict the failure of vessels with more than one flaw in the beltline region. The ability of VISA-II to correctly simulate multiple flaws was verified except to extreme cases (e.g. 100 flaws per vessel). We have since corrected the logic (Poisson distribution algorithm) to correctly treat vessels with an unlimited number of flaws.
Fred Simonen attended a workshop on PTS Analyses and Modcling Assumptions at Anaheim, California on November 21, 1991 and made a presentation entitled "VISA-II Structure and Modeling Assumptions". This workshop was jointly sponsored by the U.S. Nuclear Regulatory Commission and the Electric Power Research Institute.

Fred Simonen contributed to a coauthored a paper titled "Application of Probabilistic Fracture Analysis to Residual Life Evaluation of Embrittled Reactor Vessels" with T. L. Dickson of ()ak Ridge National Laboratory. The paper was presented at the NRC Aging Information Conference on March 24-27, 1992 at Rock* ville, Maryland.

During this reporting period we began an ongoing effort to benchmark the VISA-II code with other probabilistic fracture mechanics codes. This work is part of an NRC/EPRI organized group that is performing calculations for a set of PTS benchmark problems. We have assisted in the formulation of the benchnark problems by reviewing problem definitions proposed by Westinghouse, and by contributing our VISA-II predictions of vessel failure probabilities for these benchmark problems. There were two meetings of the henchmarking participants - Fchruary 9, 1992 at Atlanta, (icorgia and March 23, 1992 at Bethesda, Maryland.

The VISA-II deterministic calculations of temperatures, stresses and crack tip stress intensity factors have been in good agreement with calculations performed with other fracture mechanies codes. In the initial set of calculations our predictions of vessel failure probabilities differed from trends predicted by other benchmark participants. We have found differences between participants for the input data that describes the Octavia flaw size distribution. Future calculations will be based on a common set of flaw size parameters and this is expected to bring the predictions of vessel failure probabilities into closer agreement.

\subsection{Future Work}

During the next reporting period we will continue to support NRC staff in the benchmarking the VISA-II fracture mechanics code through participation in an industry wide PTS benchmarking effort. We will 


\section{Consult on Field Problems}

perform calculations with VISA-II for the expanding scries of benchmarking problems and attend meetings of participants to compare numerical results. These meetings are expected to coincide with ASME Section XI meetings (May 6, 1992 at San Antonio, Texas and August 12, 1992 at Chicago, Illinois). Between meetings we will continue to communicate with key participates at Westinghouse Electrir and at Oak Ridge National Laboratory in efforts to identify the differences in probabilistic models which can explain observed differences in numerical results. 


\subsection{Piping Inspection Task}

This task is designed to address the NDT problems associated with the piping used in light water reactors. The primary thrust of the work has been on wrought and cast stainless steel since these materials are harder to inspect than carbon steel. However, many of the subtasks' results also pertain to carbon steel. The current subtasks are: cast stainless steel inspection, surface roughness, field pipe characterization, and PISC-III activities.

The work accomplished during this reporting period is summarized in the following paragraphs:

- Cast Stainless Steel Inspection - The objective of this subtask is to evaluate the effectiveness and reliability of ultrasonic inspection techniques on LWR components containing cast stainless steel material. Far-side weld inspection is included in the scope of this work since the ultrasonic field passes through weld metal. Activities for this reporting period included an investigation of low frequency ultrasonic techniques inherently insensitive to macrostructural effects, a fracture mechanics evaluation aimed at estimating "critical" dimensions of circumferential cracks in CCSS primary pipe sections, and investigating the feasibility of implementing "adaptive ultrasonics" to the inspection of coarse grained materials.

- Surface Roughness Conditions - The objective of this subtask is to quantify and develop requirements to limit the adverse effects of surface conditions upon an ultrasonic inspection. In order to foster collaboration between CNDE and PNL, Margaret Greenwood visited CNDE in December 1991 and had extensive discussions with Bruce Thompson, Ali Minachi, and Isaac Yalda about implementing the CNDE model at PNL. Extensive experiments were performed using the Brockman $(x-y)$ scanner. The ultrasound beam was directed toward 10, 30, and 60 mil steps and also with no step so that the beam impinged normal to the surface, produced a $45^{\circ}$ longitudinal wave in steel, and produced a $45^{\circ}$ shear wave in steel. $\mathrm{C}$-scan images were obtained for these 12 cases. When a $45^{\circ}$ longitudinal wave is produced in steel, it is also accompanied by a $21.7^{\circ}$ shear wave. A derivation, which assumed plane waves, showed that the longitudinal and shear waves should be separated in time by 2.9 microseconds. When a four-cycle tone burst was used, these two signals were seen on the oscilloscope and separated by the expected time. It is possible to obtain C-scans for both the longitudinal and shear signals. The latest model improvement at CNDE considers the propagation of ultrasound from the steel surface into the water, where the microprobe receives the signal, by including appropriate transmission coefficients. As a result, much better agreement between theory and experimental data results was found.

- $\quad$ Field Pipe Characterization - The objective of this subtask is to provide pipe weld specimens that can be used for studies to evaluate the effectiveness and reliability of ultrasonic inservice inspection (UT/ISI) performed on BWR piping. Documentation of the five safe-ends removed from the Monticello nuclear power station are no longer needed for any programmatic work. Processes to dispose of these samples are still under review to meet the new requirements for disposal required by state and federal agencies.

- $\quad$ PISC-III Activities - This activity involves participation in the PISC-III program to ensure that the work addresses NDE reliability problems for materials and ISI practices on U.S. LWRs. This includes support for the co-leader of Action 4 on Austenitic Steel Tests (AST); providing a sector of the Hope Creek reactor pressure vessel containing two recirculation system inlet nozzles; coordination of the inspections to be conducted by U.S. teams on the various actions; input to the studies on reliability and specimens for use in the parametric, capability, and reliability studies of the AST. During this reporting period, coordination was provided for the schedule and circulation of the three sets of specimens in the Capability study.

\subsection{Cast Stainless Steel Inspection}

\subsubsection{Introduction}

The objective of this task is to evaluate the effectiveness and reliability of ultrasonic inspection of cast materials used within the primary pressure boundary of LWR's. 
Piping Inspection

Due to the anisotropic and nonhomogeneous nature of coarse grained cast materials, reliable and effective ultrasonic inspections are difficult to perform. The large grain size relative to the acoustic pulse wavelength strongly affects propagation of ultrasound by causing severe attenuation (primarily due to scattering), significant changes in acoustic velocity, and mode conversions. Refraction and reflection of the sound beam may occur at the grain boundaries, resulting in ficld skewing and partitioning, resulting in poor signal-to-noise ratios, false reporting of defects, incorrect reporting of defect location, and specific volumes of the material not being examined.

These inspection problems are common to structures such as cladded pipe, inner-surface cladding of pressure vessels, statically cast elbows, statically cast pump bowls, centrifugally cast stainless steel (CCSS) piping, dissimilar metal welds, and weld-over!ay-repaired pipe joints.

CCSS Piping is used in the primary reactor coolant loop piping of 27 pressurized water reactors (PWRs) manufactured by the Westinghouse Electric Corporation. However, CCSS inspection procedures continue to perform unsatisfactorily due to the coarse maciu. structure that characterizes this material. The major macrostructural classifications are columnar, equiaxed, and a mixed columnar-equiaxed macrostructure of which the majority of field material is believed to be the latter.

\subsubsection{Status of Work Performed}

Activities during this reporting period began with planning meetings with Dr. M. S. Good and Dr. S. R. Doctor to discuss task priorities, work scope, milestones, and funding considerations. This year's activities were focused on investigating low frequency, macrostructurally tolerant techniques, and adaptive ultrasonics. The initial investigation of low frequency UT was to apply a simplistic approach to the problem utilizing conventional low frequency probes and hardware. The bulk of the work then consisted of further refinement of a more sophisticated technique by optimizing the data acquisition hardware, inspection mode and frequency, improving the transducer design, and implementing a signal processing algorithm. The initial investigation of the adaptive ultrasonics methodology included software testing and development and optimization of the data acquisition hardware.

An in-depth literature search and review (with regard to the NDE of anisotropic media) was initiated, a change in lask leadership occurred, and communications were made with Dr. Phillipe Dombret of AIB Vincotte (Belgium) regarding their low-frequency investigations and search unit developm $\%$. Mectings with Dr. F. A. Simonen were held . Escuss the initiation of fracture mechanics evaluations in order to determine the critical flaw size in cast materials as a function of aging, pipe dimensions, etc., and its relationship to structural integrity. Also, mectings with Dr. B. P. Hildebrand resulted in the establishment of the work scope and plan with regard to the experimental investigation of adaptive ultrasonics.

A Science and Engineering Research Scholarship (SERS) student from the University of California at Santa Cruz. was interviewed for a 5-month internship. He accepted our offer and is currently focusing his efforts on the development of adaptive UT software. His work has consisted of developing a post-processing algorithm for phase compensation of the deformed wavefront of an acoustic pulse through coarse grained material. Preliminary results are encouraging, but more work on data acquisition, completion of software development and documentation, and an overall assessment of the adaptive UT methodology is needed to effectively cvaluate the application of this technique to coarse grained matcrials.

Refinement of the low frequency UT technique has included optimization of the wave mode, investigation of various signal processing techniques, acquisition of specialized hardware, and improved design characteristics of an initial set of search units. This work required communications with Harisonics Laboratory and Sigma Transducers, on fabrication feasibility of low frequency search units. Currently, we are focusing on evaluating significant factors that impede or enhance our UT performance through $60-75 \mathrm{~mm}$ thick pipe sections. These factors include:

- Incident angle and frequency (with regard to resolution)

- Pulse length as function of frequency and grain size

- Signal-to-noise ratio 
- Transducer type (specific piczoclectric materials)

- Implementation of specialized data acquisition hardware Concurrently, fracture mechanics cvaluations on large diameter (28-32" OD) piping, with regard to estimating critical crack sizes, are underway, and are primarily based on ductile tearing of thermally aged CCSS where mechanical and thermal fatigue crack growth mechanisms are being considered. This work has included communications with key personnel at Argonne National Lab (ANL) and Battelle Columbus, as well as utilization of available information in the literature.

Currently, due to DOE purchasing guidelines, PNL is unable to initiate purchase requisitions in a timcly manner; therefore, the date for a project milestone will need to be changed. Hardware required to perform experiments in March will not be arriving until the first week of June. A second order is not expected to be received before mid-July. This means that imperative experimental work on low frequency UT will not be completed until late July. Time will be needed to institute an effective evaluation and assessment of the work performed in order to generate a status report on these studics.

\subsubsection{Future Work}

CCSS work for the second half of this reporting period will focus on acquiring procured items and performing low frequency experimental work. An assessment of signal processing algorithms and low frequency detection performance will culminate in an overall assessment of the technique, resulting in a letter report to be submitted in August 1992. Adaptive ultrasonics work will focus on acquiring more data, completion of software development and documentation, and assessment of adaptive UT methodology. This will result in a letter report that consists of an evaluation of effectively applying this method to coarse grained materials, and will be submitted in October 1992.

Work planned for FY93 may include an in-depth study of the reliability and possible field implementation of the low frequency UT technique, the development of a real-lime phase aberration correction system for UT imaging in CCSS, and explore the possibility of combining the adaptive ultrasonics technique with SAFT pro- cessing. Far-side inspection and dissimilar metal welds work will include sample acquisition and metallography, and the acquisition of ultrasonic field maps to document ficld distortion.

\subsection{Surface Roughness Conditions}

\subsubsection{Introduction}

The objective of this task is to quantify and develop requirements to limit the adverse effects of surface conditions upon an ultrasonic inspection.

To achicve this objective there has been a cooperative effort between PNL and the Center for Nondestructive Evaluation (CNDE) at Iowa State University (ISU). An isotropic model was developed at CNDE, with EPRI funding, and this model is being validated at PNL, with NRC funding. Once validated, this model will be used as an engincering tool to study effects of any type of surface condition.

Past efforts include a simple modelling exercise to see how the central ray from a transducer is affected as the transducer approaches and passes over a step discontinuity. This modeling activity was used to gain experience at PNL for using the CNDE model and to gain an overvicw of problems associated with the step discontinuity in ultrasonic testing. Also, a joint paper by CNDE and PNL will be prepared and presented at the annual "Review of Progress in Quantitative Nondestruclive Evaluation" conference comparing the experimental data with the isotropic model. In addition, the first version of the CNDE model was transferred to PNL. clectronically.

\subsubsection{Status of Work Performed}

In order to foster the collaboration between CNDE and PNL, Margaret Greenwood visited lowa State University in December 1991. She met and had extensive discussions with Bruce Thompson, Ali Minachi, and Isaac Yalda. This was a very productive visit and the topics discussed included the theoretical basis for the model, the structure and organization of the computer code, and the code input parameters. Because the CNDE model has no supporling documentation, this visit was a vital step toward model validation by PNL. 
Greenwood and SERS student Josef Mai performed extensive experiments on the step discontinuity using the Brockman $(x-y)$ scanner. C-scan images were obtained for the following 12 cases: The ultrasound beam was difrected toward 10, 30; and $60^{\circ}$ mil steps and also with no step so that it was a) normal to the surface b) produced a $45^{\circ}$ longitudinal wave in steel and c) produced a $45^{\circ}$ shear wave in stecl. In case b) a shear wave in steel is also produced at an angle of $21.70^{\circ}$. A derivation, which assumed that the longitudinal and shear waves to be plane waves, showed that the microprobe would sense the longitudinal wave first and the shear wave 2.9 microseconds later. This time difference was independent of the position of the microprobe. A 4 cycle tone burst was used for these measurements and the longitudinal and shear signals could be separated in time and viewed on the oscilloscope. The A-scan was gated across the desired region to produce a C-scan for the longitudinal mode at $45^{\circ}$ and another for the shear mode at $21.7^{\circ}$. The derivation also shows that the time separation of the two signals is proportional to the thickness of the plate. Thus, the time separation can be increased by using a thicker stecl plate.

Model improvements continued at CNDE. Previously, the model calculated the pressure on the bottom surface of the sted plate. However, measurements are obtained by a microprobe that is several millimeters from the steel surface. The latest improvement considers the propagation from the steel surface into the water by including the appropriate transmission coefficients. Using the improved code results in much betler agreement between theory and experiment. This improved code is now available for use at PNL.

\subsubsection{Future Work}

We plan to compare the experimental measurements with the CNDE model calculations, which will be an important step toward validation. We will also continue experiments on the step discontinuity using a thicker plate to achieve a greater separation in time between the longitudinal and shear signals. During the next fiscal year, we will work on the other geometries, determine worst-case geometries (WCG), and make ASME Code recommendations.

\subsection{Field Pipe Characterization}

\subsubsection{Introduction}

The objective of this subtask is to provide pipe weld specimens that can be used for studies to evaluate the effectiveness and reliability of ultrasonic inservice inspection (UT/ISI) performed on BWR piping. Documentation of the five safe-ends removed from the Monticello nuclear power station are no longer needed for any programmatic work. Processes to dispose of these samples are still under review to meet the new requirements for disposal required by state and federal agencics.

\subsubsection{Status of Work Performed}

This task is completed except for the disposal of the 5 safe-ends that were acquired on this task. This is not as simple a matter as in the past since the specimens are radioactive and because of the lead that was wrapped around the specimen for shipment, these are considered mixed waste. Review of new requirements for disposal and the funding to cover the costs are the things being examined at this time. When the information gathered is sufficient that specific recommendations for a course of action can be proposed to the NRC, then this will be done and a plan established for conducting the disposal.

\subsubsection{Future Work}

Bury the safe-ends as soon as possible.

\subsection{PISC-III Activities}

\subsubsection{Introduction}

The objective of this subtask is to contribute to the international Programme for the Inspection of Steel Components III (PISC III) to facilitate current studies on the reliability, capability, and parametric analysis of NDE techniques, procedures, and applications. This includes full-scale vessel testing; piping inspections; and human reliability, real components, nozzles and dissimilar metal welds, and modeling studies on ultrasonic interactions. These data will be used in quantifying the 
inspection reliability of ultrasonic procedures and the sources and extent of errors impacting reliability.

The primary arcas in which PNL participated include Action No. 1 on Real Contaminated Structures Tests (RCS), Action No. 2 on Full-Scale Vessel Tests (FSV), Action No. 3 on Nozzles and Dissimilar Metals Welds (NDM), Action No. 4 on Round-Robin Tests on Austenitic Steels (AST), Action No. 6 on Ultrasonic Testing Modeling (MOD), and Action No. 7 on Human Reliability Exercises (REL). These actions are being followed to ensure that conditions, materials, and practices in the U.S. are being included in the work so that the results are transferable to the U.S.

\subsubsection{Status of Work Performed}

The main activitics that were conducted during this reporting period involved the participation in PISC III meetings to plan activities and to review progress of the various actions. The inspections of the AST capability studies has been hard to fulfill because of the difficulty in getting teams from the USA to participate. Mr. Jack Spanner took on the challenge of contacting organizations that perform ISI on LWRs in the USA and was able to get a very respectable commitment to participate in these studies. There were a total of 8 teams identified that would be inspecting the wrought stainless steel specimens. In addition, commitment was received from some of these organizations to participate in the wrought-to-cast and the cast-10-cast studies. However, the specimens for these later two studies will not be in the USA until the first three months of 1993. The participation of the inspection organizations in the USA is greatly appreciated and will make the results from these studies of greater benefit to knowing where the state-of-the-art is for the inspection of piping components.

It has become apparent that there will not be a reliability study on cast materials. There simply will not be adequate time to conduct this kind of study and there are insufficient funds to fabricate the number of specimen required for a reliability study. In addition, the wrought stainless steel study has been reduced in scope and will focus on the detect; $n$ and characterization of IGSCC in pipes removed from the field. Again it is in part time and cost which forces this constraint. Rcgardless, this reliability study is still important since it will allow the evaluation of person$\mathrm{nel} / \mathrm{equipment} / \mathrm{procedures}$ on real defects, on real components and with a time schedule that provides adequate time for conducting the inspections and interpreting the results. It is expected that the teams in the USA will conduct their inspections in the fall of 1992 at an inspection site located at PNL in Richland, WA.

The wrought stainless stecl capability study will be completed in carly fall of 1992 so all data should be available for initial analysis by the start of 1993 . The plan is for the specimens in this study to be destructively analyzed by an organization in Japan that is part of the contribution in kind that the Japanese are providing.

\subsubsection{Future Work}

Continue the studies that have been initiated and support the analysis of data, the courdination of USA teams, the shipment of specimen sets and the attendance at PISC III meetings including the Management Board, AST planning mectings and data analysis group (DAG 4). 


\subsection{References}

Vo, T. V., B. F. Gore, L. J. Eshbach, and F. A. Simonen, "Probabilistic Risk Assessment-Based Guidance for Piping Inservice Inspection." Nuclear Technology, Vol. 88 (1), American Nuclear Socicty, La Grange Park, Illinois, 1989.

Vo, T.V., B.W. Smith, F.A. Simonen, and S.R. Doctor, "Development of Generic In-Service Inspection Priorities for Pressure Boundary Systems," Nuclear Technology, Vol. 92 (291), American Nuclear Society, La Grange Park, Illinois, 1990.
U.S. Nuclear Regulatory Commission (NRC), NUREG1150, Vol. 1, "Severe Accident Risks: An Assessment for Five U. S. Nuclear Power Plants, Final Summary," 1990.

Whecler, T. A., S. C. Hora, W. R. Cramond, and S. D. Unwin, NUREG/CR-4550, Vol. 2, "Analysis of Core Damage Frequency from Internal Events: Expert Judgment Elicitation," Sandia National Laboratories, Albuquerque, New Mexico, 1989. 


\section{DISTRIBUTION}

No. of

Copies

\section{OFFSITE}

J. Muscara

NRC/RES

Mail Stop NS 217C

2 A. J. Hiser, Jr. NRC/RES

Mail Stop NS 217C

C. Z. Serpan

NRC/RES

Mail Stop NS 217C

G. Johnson

NRC/RES

Mail Stop 7D-4

M. R. Hum

NRC/NRR

Mail Stop 7D-4

J. Strosnider

NRC/NRR

Mail Stop 7D-4

J. P. Durr

NRC/Region I

M. C. Modes

NRC/Region I

A. R. Herdt

NRC/Region II

J. J. Blake

NRC/Region II

J. Jacobson

NRC/Region III
No. of

Copies

\section{FOREIGN}

J. R. Tomlinson

NDT Application Centre

Nuclear Electric plc

Timpson Road

Wythenshawe

Manchester M23 OLL

United Kingdom

\section{ONSITE}

50 Pacific Northwest Laboratory

E. S. Andersen

R. E. Bowey

D. M. Boyd

S. H. Bush

A. A. Diaz

S. R. Doctor (28)

J. R. Friley

M. S. Good

B. F. Gore

M. S. Greenwood

R. V. Harris

P. (j. Heasler

R. L. Hockey

R. J. Kurtz

F. A. Simonen

J. C. Spanner

T. V. Vo

Publishing Coordination

Technical Report Files (5) 

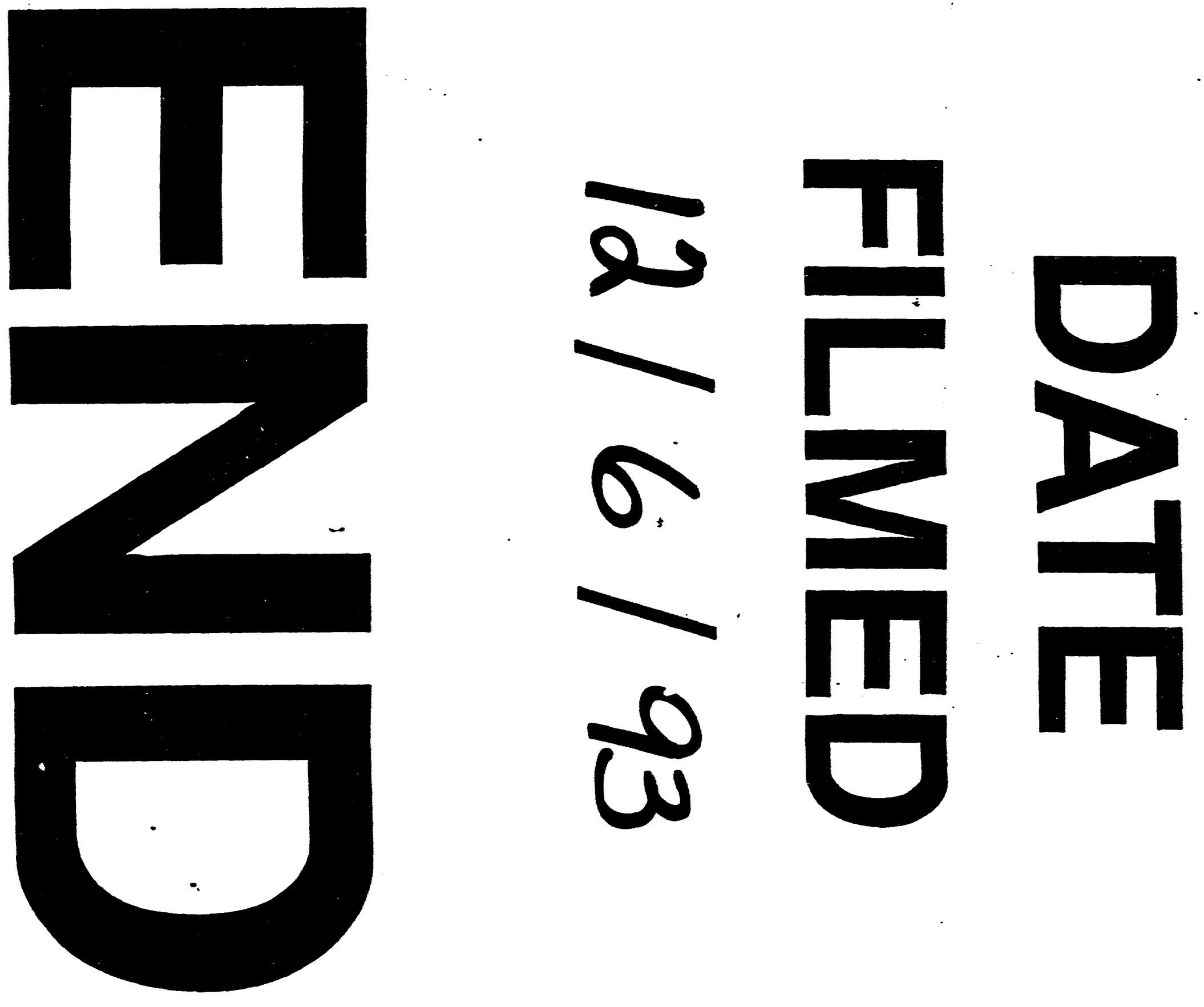
